\title{
La arquitectura de la democracia
}

La arquitectura no está sólo basada en el dogma y la autoridad, sino que brota de la vida cotidiana como expresión de la comprensión de la naturaleza por parte del hombre y de los conocimientos que él tiene de los otros y de sí mismo.

En nuestro pais y nuestras ciudades se han dado cambios profundos: calidades tradicionales que caracterizaban nuestros asentamientos humanos se han alterado por completo o han desaparecido. En el sentido espacial, los nuevos asentamientos se han transformado en aglomeraciones (aglomerados) dispersas de unidades habitacionales donde el sentido del lugar se ha ido perdiendo.

El tejido urbano se ha desintegrado, la coherencia que caracterizaba los espacios urbanos se altera día a día; nudos, recorridos y dominios pierden su propia identidad y la ciudad no logra tener más una imagen y un significado comprensibles.

- De esto se deriva que el carácter predominante de las nuevas construcciones de nuestras ciudades y del ambiente "moderno" es monótono y los tentativos de interrumpir esta monotonía general parecen como fantasías arbitrarias, con el uso siempre más frecuente de grandes paredes ficticias de trasfondo teatral con caracteres inconsistentes que reconstruyen ambientes "a la moda" foráneos y alienantes para el consumo del tiempo libre (enormes vallas publicitarias, restaurantes y centros comerciales que proponen ambientes particulares y ajenos).

\section{Periferización y separación}

Todos los hombres tienen derecho a un territorio, a una vivienda y a servicios e infraestructuras básicas. La falta de una casa, que reúna las condiciones mínimas para la supervivencia de la familia, es una de las causas más frecuentes que genera malestar y desequilibrio social.

Nuestras ciudades no se decentralizan hacia los poblados periféricos, sino que se dilatan ocupando territorios siempre más vastos; mientras que en su interior quedan amplias áreas deterioradas y mal utilizadas: fábricas insertadas muchas veces violentamente en el interior del tejido urbano o apenas afuera de sus límites, barrios sobrepoblados privados de los servicios básicos y predios baldíos donde existieron construcciones que se han dañado por incendios o terremotos, hoy convertidos en eventuales parqueos, basureros o simplemente abandonados.

Casi todos los equipamientos (aceras, verjas, plazas, casas comunales, etc.) y las viviendas llevan consigo el signo de una tecnología rígida, esquemática y pobre, tendiente a minimizar los costos y casi siempre desinteresada respecto a las necesidades de los ciudadanos y los recién urbanizados. De esto resulta una fragmentación territorial que se alarga como mancha de aceite o como tramas geométricas al espacio urbano donde las relaciones son muchas veces superficiales o no existen.

Cada urbanización nueva si no se construye muy lejos del centro tiende a transformarse en poriferia antes que la obra finalice; más que de periferia en el sentido físico es más correcto hablar de proceso de periferización social generalizada.

El modelo al cual casi todos los profesionales y los técnicos de la proyección arquitectónica se refieren es el modelo de la separación. La ideología 
política que condiciona este modelo es la de favorecer la propiedad privada de cualquier tipo de vivienda. Aunque atomizada, la idea de composición arquitectónica consecuente es la de la célula unifamiliar con puertas y ventanas, que dan a un territorio externo degradado y socialmente disgregado.

De hecho, las encuestas de opinión pública realizadas en los barrios más pobres para conocer las condiciones de los habitantes urbanos, han arrojado conjuntamente y de manera contradictoria tanto las denuncias por la falta de servicios, espacios verdes, higiene ambiental y seguridad por el desinterés de las autoridades, como el sentimiento de orgullo por poseer su propia vivienda y de pertenecer a una gran ciudad.

\section{Participación ciudadana}

El crecimiento incontrolable de la ciudad y la pérdida de forma y significado del centro histórico no son fenómenos sólo actuales. La expansión de las nuevas agregaciones urbanas a lo largo de diferentes direcciones y muchas veces en territorios con alta degradación física, "consumiendo" grandes cantidades de espacio, constituye un inmenso problema de naturaleza política, económica y social que debemos enmarcar en una perspectiva urbanística y arquitectónica de participación de los distintos actores (sujetos) sociales.

Tomando en cuenta los efectos que la pérdida de la forma urbana tiene sobre la identidad de los ciudadanos y sobre la relación de los hombres con su propio hábitat, se necesita favorecer la participación de todos los habitantes para afrontar los problemas del vivir en la ciudad y proyectar y decidir sobre su futuro.

Por eso se debe afrontar política y culturalmente el problema de la educación urbana en las áreas de la gestión del territorio, de la identidad de la ciudad, de la viabilidad, del transporte, de las condiciones de los lugares de trabajo, de la seguridad, del funcionamiento de los servicios y de las infraestructuras, de la protección y conservación de los espacios verdes y del paisaje, para desarrollar aquellas "culturas diferentes" que podrían contribuir a la construcción de una alternativa original al geometrismo mínimo y pobre de la época tecnológica. Puesto que la ciudad, diciéndolo con las palabras de Jean Gottman, es una organización dinámica, siempre cambiante y en transición.

\section{Crisis ambiental y crisis humana}

El asentamiento urbano como lugar de vida comunitario ha perdido su valor y los edificios modernos de las instituciones se construyen en grandes vacíos sin que exista una relación coherente con el paisaje y el contexto urbano.

En estas construcciones se vive una vida artificial en un espacio tecnológico donde con dificultad se logra diferenciar lo que está arriba -cielo- de lo está abajo - tierra-, y en el interior del edificio se percibe la sensación de nulidad con una superficie neutra y plana como el cielo falso y las ventanas todas iguales y estandarizadas. La variedad y la calidad casi siempre han desaparecido y con razón se puede hablar de crisis ambiental que implica consecuentemente una crisis humana, conociendo cómo la identidad humana depende en general del desarrollo en un ambiente con determinadas características.

Paradójicamente, la situación actual es el resultado de la aspiración por mejorar el ambiente humano. La arquitectura moderna de hecho empezó con la intención y la aspiración de construir viviendas que respondieran satisfactoriamente a las nuevas exigencias humanas.

En 1942, Le Corbusier escribía en La Mesón des Homme (La casa del hombre): "el hombre habita mal, ésta es la razón verdadera y profunda de los revolvimientos actuales", y antes, en 1923, en Vers Une Architecture (Hacia una Arquitectura) indicaba como: "deben tenernos compasión porque habitamos en casas indignas que nos dañan en lo físico y en lo moral".

El Esprit Nouveau (El Espiritu Nuevo) implicaba una nueva manera de vivir que impulsaba al hombre a seguir el desarrollo orgánico de la existencia (niño, joven, adulto, casado, soltero, mujer, hombre) y ayudar al hombre alienado contemporáneo a reencontrarse y entrar nuevamente a poseer una existencia auténtica y significativa. A tal fin era necesaria la libertad y la identidad.

\section{Libertad e identidad}

La liburtad como rechazo y liberación de los regímenes autoritarios y como nuevo derecho a las opciones y la participación.

La identidad como un retorno, una propuesta cultural para el hombre que preste atención a lo 


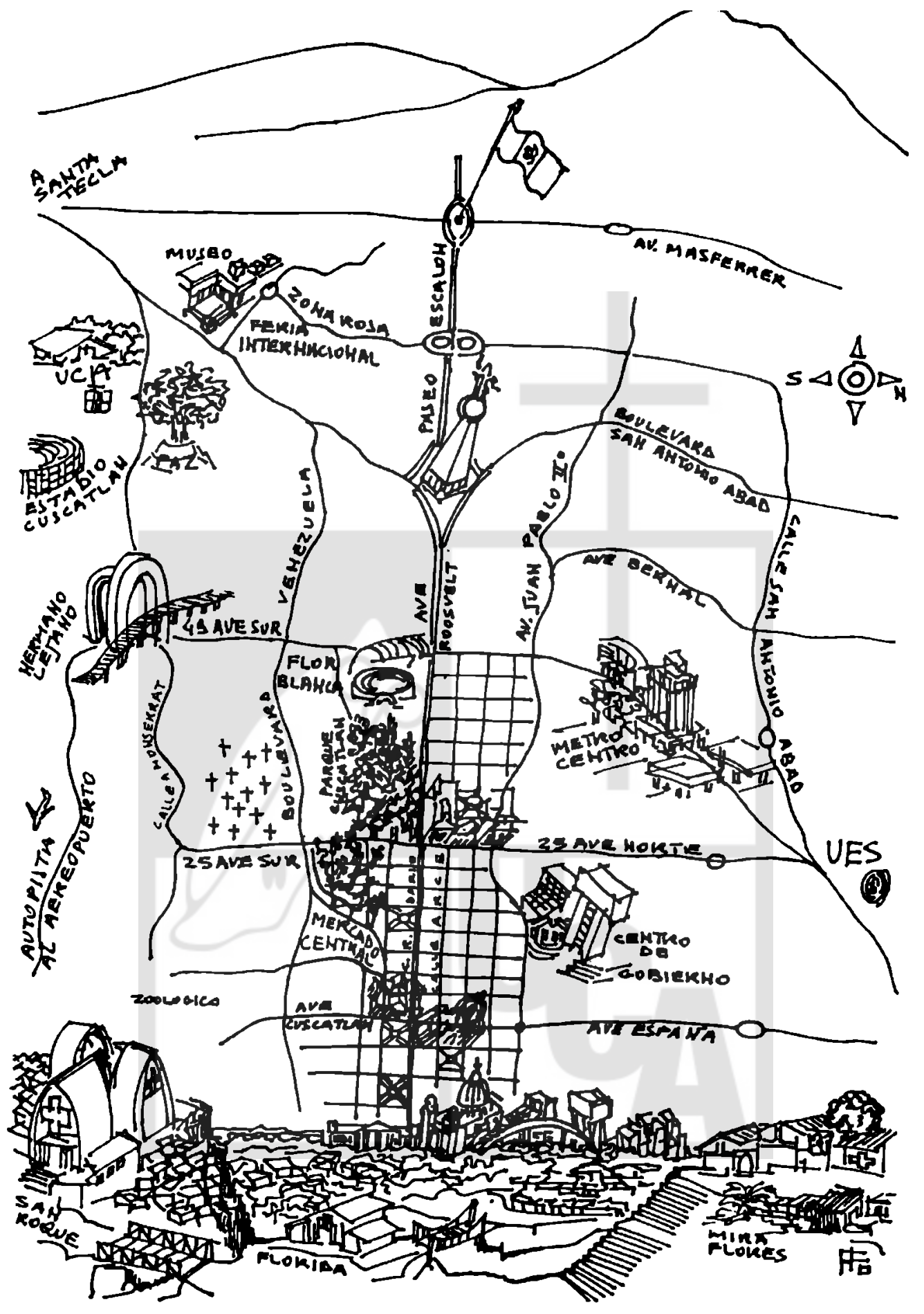

La ciudad lugar de mediación entre la "globalización" de la historia y la "localización" de la vida de la gente. 
esencial y un reencuentro con sus orígenes a través de un proceso educativo.

La obra de Frank Loyd Wright, el primer pionero de la arquitectura moderna, también ha sido condicionada desde el comienzo por un fuerte deseo de realidad; él, utilizando materiales naturales, manifestaba el deseo del retorno a los fenómenos concretos, o sea, a un sentido más profundo de la realidad.

Wright primero buscó una respuesta a la demanda de "libertad" al destruir la "casa-caja" tradicional, refugio del individuo y de su familia y crea una nueva interacción entre espacio interior y espacio exterior, utilizando paredes continuas que dirigen y unifican el espacio. Lo interior se transformó en aquel espacio personal a partir del cual el individuo puede experimentar y expresar un nuevo sentido de libertad y participación.

Los insirumentos concretos elaborados por Wright para ofrecer a las personas una "casa abierta" y su concepción sobre la arquitectura de la democracia han suscitado una profunda impresión que originó una nueva manera de pensar la arquitectura.

Mientras la arquitectura sea determinada desde arriba, las casas se limitarán a reflejar formas significativas desarrolladas en relacion con la iglesia, el palacio, las instituciones del poder y las formas de vida de la cultura predominante.

Por el contrario, la arquitectura de la democracia se origina desde la residencia del hombre; las otras funciones espaciales para el trabajo, la educación, la cultura, la salud y la diversión se consideran extensiones del hábitat y no se fundamenta más sobre el dogma y la autoridad, sino que brota de la vida cotidiana como expresión de la comprensión de la naturaleza por parte del hombre y de los conocimientos que él tiene de los otros y de sí mismo.

El papel de la nueva arquitectura es hacer conciencia en el hombre del sistema en el que vive y sanar la ruptura entre pensamiento y sentimiento que es un producto característico de la sociedad burguesa.

Los temas arquitectónicos más complejos (iglesia, casa comunal, infraestructuras sanitarias, socia- les y culturales, fábricas, estadios, etc.) representan así lo que el hombre debe conquistar viviéndolo.

\section{Crisis del movimiento moderno frente a la pro- blemática urbana}

Hemos demostrado cómo las posiciones iniciales del Movimiento Moderno han sido profundamente significativas, pero cuando el carácter místico del primer período del Modernismo se transfirió a nivel urbano, lo que era una composición ingeniosa de formas se convirtió en una "monotonía estéril".

La primera razón se debe a la crisis del problema urbano, de la ciudad, porque como lugar urbano, el asentamiento modemo está concebido como una "casa gigantesca" y los barrios se proyectan y construyen como grandes plantas abiertas sin tener verdaderos y propios interiores urbanos significativos, sin tener relación entre interior y exterior y sin distinguir entre el dominio público y el privado.

En el plan espacial, la ciudad moderna es por eso el resultado de una confusión de escala: el esquema funcional valioso para la casa se transfiere ciegamente a otro nivel, el de la ciudad.

La segunda razón se debe a la difusión del "estilo internacional", que concibe una arquitectura sin carácter ni local, ni regional y que debe adecuarse en cada lugar a los mismos principios como "producto inevitable y lógico de las condiciones intelectuales, sociales y técnicas de nuestros tiempos modernos"l.

Es importante saber que la esencia del asentamiento humano consiste en la agrupación. Agrupar significa reunir conjuntamente significados diferentes.

La arquitectura estandarizada, igual en cada lugar, fruto de una sola cultura, lógica, funcional, homogénea y excluyente, comunica sobre todo el mensaje de un mundo moderno-global con una concepción de cierta manera antiurbana, porque la apertura no puede ser agrupada. Apertura significa salida, agruparse significa reencontrarse.

No es justo atribuir al Movimiento Moderno carencias que pertenecen solamente a una etapa específica de su historia y a sus imitadores que no han comprendido a fondo los problemas del mundo actual.

1. Gropius, W. The New Architeture and the Bauhaus, Londres, 1935, p. 18. 
De hecho, sus más valiosos representantes desde hace 20 ó 30 años se han preocupado de los problemas actuales más importantes, y han mostrado mayor atención por el problema ambiental.

En 1951, el Congreso CIAM - Congresos Internacionales de Arquitectura Moderna- trató el tema "El Corazón de la Ciudad", es decir, el problema de un núcleo agrupador entre el tejido abierto del asentamiento moderno. S. Giedion ex presaba: "el interés contemporáneo para el corazón de la ciudad hace parte de un proceso general de humanización, de un retorno a la dimensión humana y a la afirmación de los derechos de la per'sona..."2.

En 1954, en su ensayo sobre El Nuevo Regionalismo auspiciaba un renovado respeto para "la forma de vida" que debe ser analizada con "respeto" antes de pasar a la proyectación.

"El Nuevo Regionalismo está generado y motivado por la reverencia hacia la persona y por el deseo de satisfacer las necesidades materiales y espirituales propias de cada lugar"3.

\section{Papel de la arquitectura contemporánea}

La reflexión sobre la función de la arquitectura contemporánea nos lleva a cuestionarnos sobre cual debe ser el papel de los arquitectos para crear, proyectar y construir aquellos espacios que permitan a la población liberarse de una existencia ligada sólo al consumo y a la lucha por su sobrevivencia.

Los arquitectos no pueden ser simples colaboradores del poder constituido y ejecutar cualquier cargo sin tomar en consideración la consecuencias de sus acciones sobre la sociedad y el ciudadano.

En su actividad profesional, los arquitectos deben coherentemente tener presente lo que escribió Giedion en su libro Espacio-Tiempo y Arquitectu$r a:$ "la arquitectura hace tiempo ha dejado de ser el monopolio de especialistas, agnósticos y especulativos que realizan puntualmente el deseo de sus clientes. Ella ahora ha adquirido el valor de afrontar la vida"4.

Considerando la arquitectura desde este punto de vista, nuestro trabajo será más significativo y motivado; además, lograremos liberarnos de las abstracciones y de la alienación, también nos permitirá acercarnos a las cosas y reconducirnos a aquel mundo de la vida cotidiana donde es existencialmente radicada la arquitectura con mayor imaginación y favoreciendo la participación de los habitantes de nuestras ciudades.

"La educación a través del arte" se demuestra cada vez más necesaria y la principal obra de arte sobre la cual la educación humana debe basarse es el lugar que nos confiere nuestra identidad. Sólo cuando comprendamos nuestros lugares, podremos participar activamente y contribuir a sus historias.

Los sueños que acompañan las acciones humanas deberían nutrirse de los lugares en donde vive la gente 5 .

Concluimos con las palabras del arquitecto italiano G. De Carlo dirigida a los estudiantes de arquitectura: "los problemas de la arquitectura contemporánea no tienen nada que ver con el Hombre Universal. Se refieren más bien al hombre común y siempre diferente, que necesita de viviendas, escuelas, edificios públicos, carretera, plazas, barrios etc., siempre distintos para cada ambiente, para cada situación y para cada circunstancia.

Estos problemas no se resuelven como por milagro, resucitando viejos lenguajes momificados. Se enfrentan sometiendo a una crítica rigurosa y profunda todos los hechos arquitectónicos que nos han precedido, buscando los medios para comprender mejor y ser partícipe de las necesidades de la gente para la cual queremos trabajar, clarificando el sentido de nuestro trabajo de arquitectos en la sociedad en la cual vivimos"6.

2. Giedion, S. Architeture You and Me, Cambridge, 1978, p. 127.

3. Giedion, S. Architeture You and Me, Cambridge, 1978, p. 145.

4. Giedion, S. Spazio, Tempo e Architettura, Milano, 1954, p. 582.

5. Moore, C. y Lyndon, D. The Place of Houses, Nueva York, 1075.

6. De Carlo, G. Problemi concreti per i giovani delle colonne, Casabella Continuitá, No. 204, 1995. 